\title{
Lightning Discharge and Fundamentals of Lightning Protection
}

\author{
Vladimir A. Rakov* \\ Department of Electrical \& Computer Engineering, University of Florida, Gainesville, FL, USA
}

\begin{abstract}
A review of lightning protection concepts introduced by Benjamin Franklin (18th century) and James Clerk Maxwell (19th century) is given. Modern approaches to lightning protection of various structures and systems are discussed. In particular, the widely used electrogeometrical model (one version of which is the Rolling Sphere Method) and the topological shielding are presented. Bonding requirements, needed to avoid side flashes (in air or in the soil), are discussed. Lightning parameters important for lightning protection are reviewed.
\end{abstract}

Keywords: Lightning parameters, structural lightning protection, electrogeometrical method, rolling sphere method, bonding.

\section{GENERAL PRINCIPLES}

Systematic studies of thunderstorm electricity can be traced back to May 10, 1752 in the village of Marly-la-Ville, near Paris. On that day, in the presence of a nearby storm, a retired French dragoon, acting on instructions from ThomasFrancois Dalibard, drew sparks from a tall iron rod that was insulated from ground by wine bottles. The results of this experiment, proposed by Benjamin Franklin, provided the first direct proof that thunderclouds contain electricity. Even before the experiment at Marly, Franklin had proposed the use of grounded rods for lightning protection. Originally, he thought that the lightning rod would silently discharge a thundercloud and thereby would prevent the initiation of lightning. Later, Franklin stated that the lightning rod had a dual purpose: if it cannot prevent the occurrence of lightning, it offers a preferred attachment point for lightning and then a safe path for the lightning current to ground. It is in the latter manner that lightning rods, often referred to as Franklin rods, actually work.

There are generally two aspects of lightning protection design: 1) diversion and shielding, primarily intended for structural protection but also serving to reduce the lightning electric and magnetic fields within the structure, and 2) the limiting of currents and voltages on electronic, power, and communication systems via surge protection. Primarily the first aspect will be considered here. Properly designed structural lightning protection systems for ground-based structures serve to provide lightning attachment points and paths for the lightning current to follow from the attachment points into the ground without harm to the protected structure. Such systems are basically composed of three elements: 1) "air terminals" at appropriate points on the structure to intercept the lightning, 2) "down conductors" to carry the lightning current from the air terminals toward the ground, and 3) "grounding electrodes" to pass the lightning current into the earth. The three system components must be electrically well connected. The efficacy of this so-called conventional approach to lightning protection has been well

*Address correspondence to this author at the Department of Electrical \& Computer Engineering, University of Florida, Gainesville, FL 32611-6130, USA ; Tel: 352-392-4242; E-mail: rakov@ece.ufl.edu demonstrated in practice. Neither data nor theory supports claims that non-conventional approaches, including "lightning elimination" and "early streamer emission" techniques, are superior to the conventional one.

Lightning protection system for houses proposed in 1778 is shown in Fig. (1). Modern structural lightning protection is illustrated in Fig. (2). Note that metallic roofs whose thickness is $4.8 \mathrm{~mm}(3 / 16 \mathrm{in}$.) or greater do not require air terminals (NFPA $780[3]$ ).

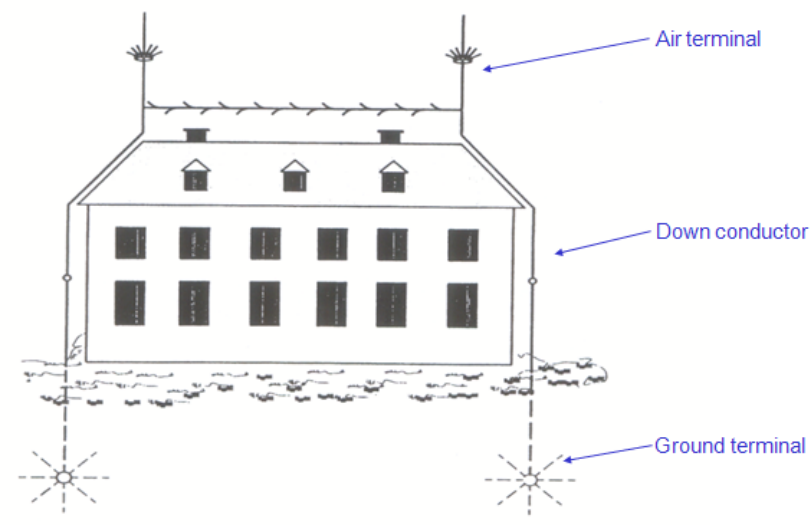

Fig. (1). Lightning protection system for houses proposed (most likely by G. Ch. Lichtenberg) in 1778. Adapted from Wiesinger and Zischank (1995) [1].

In 1876, James Clerk Maxwell suggested that Franklin rod systems attracted more lightning strikes than the surrounding area. He proposed that a gunpowder building be completely enclosed with metal of sufficient thickness, forming what is now referred to as a Faraday cage. If lightning were to strike a metal-enclosed building, the current would be constrained to the exterior of the metal enclosure, and it would not even be necessary to ground this enclosure. In the latter case, the lightning would merely produce an arc from the enclosure to earth. The Faraday cage effect is provided by all-metal cars and airplanes. Modern steel-frame buildings with reinforcing metal bars in the concrete foundation connected to the building steel provide a good approximation to a Faraday cage. As the spacing between conductors increases, however, the efficiency of the 


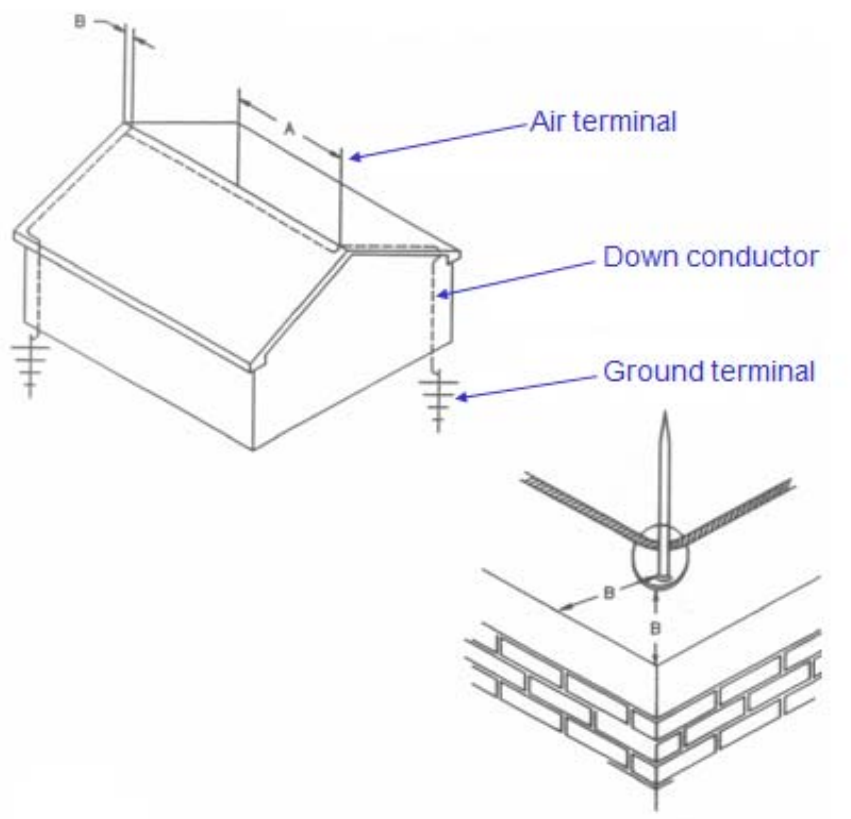

$A=20$ feet $(6 \mathrm{~m})$ maximum spacing for 10 inch $(254$ $\mathrm{mm}$ ) air terminal height or 25 feet $(7.6 \mathrm{~m})$ maximum spacing for 24 inch $(610$ $\mathrm{mm}$ ) air terminal height.

$B=2$ feet $(610 \mathrm{~mm})$ maximum spacing from corner, roof edge or ridge end.

Fig. (2). Modern structural lightning protection (UL 96A, figure 6.2, 1998) [2].

lightning protection decreases. In practice, a combination of the Franklin rod system concept and the Faraday cage concept is often used. Modern lightning protection schemes for structures containing computers or other sensitive electronics employ a technique known as topological shielding with surge suppression (see Fig. 3), which can be viewed as a generalization of the Faraday cage concept.

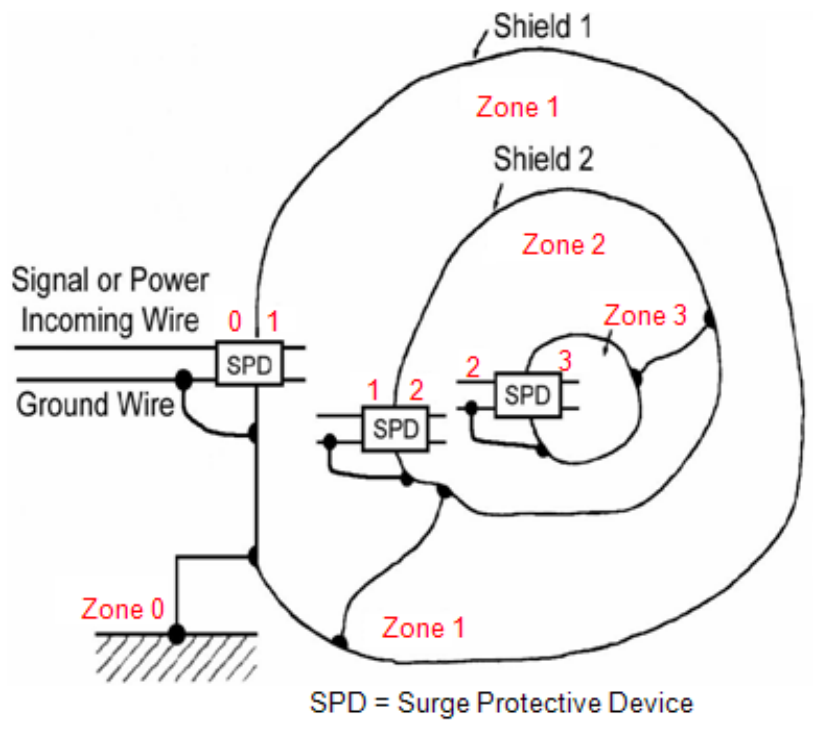

Fig. (3). The general principles of topological shielding. Adapted from Vance (1980) [4].

\section{LIGHTNING PARAMETERS IMPORTANT FOR LIGHTNING PROTECTION}

\subsection{Lightning Parameters vs Damage Mechanisms}

The type and amount of lightning damage that an object suffers depends on both the characteristics of the lightning discharge and the properties of the object. The physical characteristics of lightning of most interest are various properties of the current waveform and of the radio frequency electromagnetic fields. Four distinct properties of the lightning current waveform are considered important in producing damage: 1) the peak current, 2) the maximum rate of change of current, 3) the integral of the current over time (i.e., the charge transferred), and 4) the integral of the current squared over time, the "action integral". We now briefly examine each of these properties and the type of damage to which they are thought to be related (Rakov and Uman, 2003 [5]).

1) Peak current. For objects or systems that present an essentially resistive impedance, such as, under certain conditions, a ground rod driven into the earth, a long power line, and a tree, the voltage $(\mathrm{V})$ on the object or system with respect to remote ground will be proportional to the current, I, via Ohm's law, V = RI, where $\mathrm{R}$ is the effective resistance at the strike point. For example, a $30 \mathrm{kA}$ peak current injected into a power line phase conductor with a $400 \Omega$ characteristic impedance (effective resistance $200 \Omega$ since $400 \Omega$ is "seen" in each direction) produces a line voltage of $6 \mathrm{MV}$ with respect to the earth. Such a large voltage can lead to an electric discharge from the struck phase conductor to adjacent phase or neutral conductors or to ground across insulating materials or through the air.

2) Maximum rate-of-change of current. For objects that present an essentially inductive impedance, such as, under some circumstances, wires in an electronic system, the peak voltage will be proportional to the maximum rate-of-change of the lightning current ( $\mathrm{V}=\mathrm{L} \mathrm{dI} / \mathrm{dt}$, where $\mathrm{L}$ is the inductance of the length of wire and $\mathrm{V}$ is the voltage difference between the two ends of the wire). For example, if a "ground" wire connecting two electronic systems (for example, in a communications tower and in an adjacent electronics building) has an inductance per unit length of $10^{-6} \mathrm{H} \mathrm{m}^{-1}$ 
and if 10 percent of the direct lightning current flows in the wire producing $\mathrm{dI} / \mathrm{dt}=10^{10} \mathrm{~A} \mathrm{~s}^{-1}, 10 \mathrm{kV}$ will be produced across each meter of the wire. It is easy to understand how even a very small fraction of the lightning current circulating in grounding and bonding wires can cause damage to solid-state electronic circuits that have communication, power and other inputs "grounded" at different locations.

3) Integral of the current over time. The severity of heating or burn-through of metal sheets such as airplane wing surfaces and metal roofs is, to a first approximation, proportional to the lightning charge transferred which is in turn proportional to the energy delivered to the surface. This is the case because the input power to the conductor surface is the product of the current and the more or less current-independent voltage drop at the arc-metal interface, this voltage drop being typically 5 to $10 \mathrm{~V}$. The voltage drop at the interface can be thought of as a contact potential between the two materials or the difference in the work functions of the two materials, although the situation is considerably more complex than the case of two contiguous solid conductors in that the metal surface is partially melted and the "air" arc contains metal vapor. Generally, large charge transfers are due to long-duration (tens to hundreds of milliseconds) lightning currents, such as long continuing currents, whose magnitude is in the 100- to 1,000-A range, rather than return strokes having larger currents but relatively short duration and hence producing relatively small charge transfers. Additionally, even those impulse currents which do have relatively large charge transfers cause only relatively minor surface damage on metal sheets, apparently because the current duration is too short to allow penetration of heat into the metal.

4) Action integral. The heating and melting of resistive materials, which may or may not be relatively good conductors, and the explosion of poorly conducting materials are, to a first approximation, related to the value of the action integral, that is, the time integral of the Joule heating power $I^{2}(t) R$, for the case that $R=1 \Omega$. Thus the action integral (also referred to as the specific energy) is a measure of the ability of the lightning current to generate heat in a strike object characterized by resistance R. About 5 percent of negative first strokes in ground flashes have action integrals exceeding $5.5 \mathrm{x}$ $10^{5} \mathrm{~A}^{2} \mathrm{~s}$; about 5 percent of positive strokes have action integrals exceeding $10^{7} \mathrm{~A}^{2} \mathrm{~s}$. In the case of most poorly conducting materials, this heat vaporizes the internal material and the resultant gas pressure causes an explosive fracture. In addition to heating effects, the action integral is also a measure of some mechanical effects such as the crushing of hollow metal tubes carrying lightning current, the effect being both a function of the instantaneous force which is proportional to the square of the current and the duration of application of the force. In this case, the applied force must also exceed some threshold value.

Electromagnetic fields from lightning that impinge on any conducting objects induce currents and resultant voltages in those objects. Two properties of the electromagnetic fields are sufficient to describe most of the important damaging effects, commonly the destruction of electronic components: (1) the peak values of the electric and magnetic fields and (2) the maximum rates-of-change of the fields. For certain types of unintended antennas, such as elevated conductors that are capacitively coupled to ground, the peak induced voltage on the conductors with respect to ground is proportional to the peak electric field. For other unintended antennas, such as a loop of wire in an electronic circuit, some underground communication cables, and elevated conductors resistively coupled to ground, the peak voltage is proportional to the maximum rate of change of the electric or the magnetic field. The degree of coupling of fields through holes or apertures in the metal skins of aircraft and spacecraft is generally proportional to the rate of change of the electric and magnetic fields.

\subsection{Lightning Peak Current - "Classical” Distributions}

Essentially all national and international lightning protection standards (e.g., IEEE Std 1410-1997 [6]; IEEE Std 1243-1997 [7]; IEC 62305-1 [8]) include a statistical distribution of peak currents for first strokes in negative lightning flashes (including single-stroke flashes). This distribution, which is one of the cornerstones of most lightning studies, is largely based on direct lightning current measurements conducted in Switzerland from 1963 to 1971 (e.g., Berger, 1972 [9]; Berger et al., 1975 [10]). The cumulative statistical distributions of lightning peak currents for (1) negative first strokes, (2) positive first strokes, (3) negative and positive first strokes, and (4) negative subsequent strokes are presented in Fig. (4). The distributions are assumed to be lognormal and give percent of cases exceeding abscissa value.

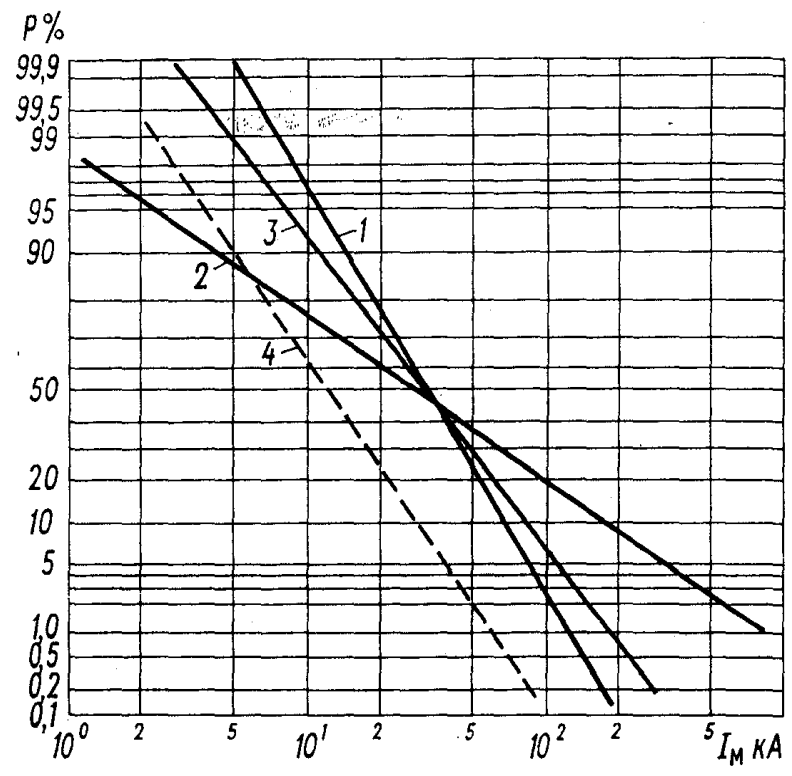

Fig. (4). Cumulative statistical distributions of lightning peak currents, giving percent of cases exceeding abscissa value, from direct measurements in Switzerland (Berger, 1972 [9]; Berger et al. 1975 [10]). The distributions are assumed to be lognormal and given for (1) negative first strokes, (2) positive first strokes, (3) negative and positive first strokes, and (4) negative subsequent strokes. Adapted from Bazelyan et al. (1978) [11]. 
Only a few percent of negative first strokes exceed 100 $\mathrm{kA}$, while about $20 \%$ of positive strokes have been observed to do so. On the other hand, it is thought that less than $10 \%$ of global cloud-to-ground lightning is positive. About $95 \%$ of negative first strokes are expected to exceed $14 \mathrm{kA}, 50 \%$ exceed $30 \mathrm{kA}$, and $5 \%$ exceed $80 \mathrm{kA}$. The corresponding values for negative subsequent strokes are 4.6, 12, and 30 $\mathrm{kA}$, and 4.6, 35, and $250 \mathrm{kA}$ for positive strokes. Subsequent strokes are typically less severe in terms of peak current and therefore often neglected in lightning protection studies. According to Fig. (4, line 3), slightly more than 5\% of lightning peak currents exceed $100 \mathrm{kA}$, when positive and negative first strokes are combined.

Berger's peak current distribution for negative first strokes shown in Fig. (4) is based on about 100 direct measurements and, as of today, is apparently the most accurate one. In lightning protection standards, in order to increase the sample size, Berger's data are often supplemented by less accurate indirect lightning current measurements obtained using magnetic links. There are two main distributions of lightning peak currents for negative first strokes adopted by lightning protection standards: the IEEE distribution (e.g., IEEE Std 1410 - 1997 [6]; IEEE Std 1243 - 1997 [7]; Anderson, 1982 [12]) and CIGRE distribution (e.g., Anderson and Eriksson, 1980 [13]). Both these distributions are presented in Fig. (5), taken from CIGRE Document 63 [14].

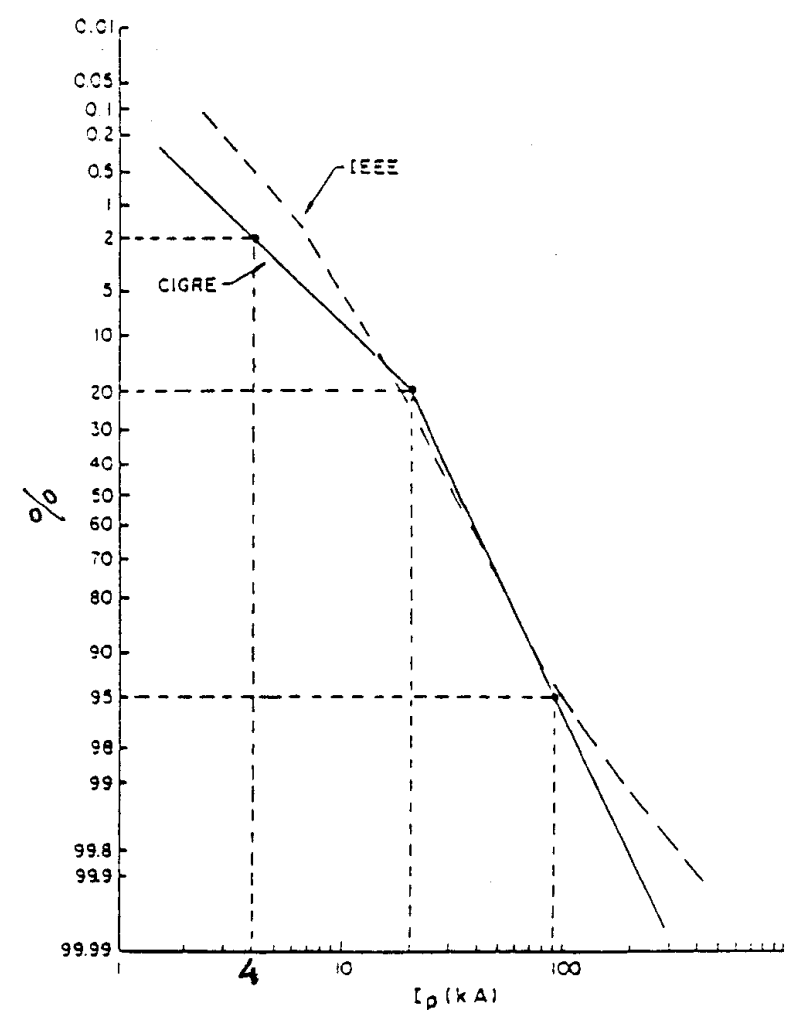

Fig. (5). Cumulative statistical distributions of peak currents (percent values on the vertical axis should be subtracted from $100 \%$ to obtain the probability to exceed, as in Fig. (4), the peak current value on the horizontal axis) for negative first strokes adopted by IEEE and CIGRE and used in various lightning protection standards. Taken from CIGRE Document 63 (1991) [14].
For the CIGRE distribution, $98 \%$ of peak currents exceed $4 \mathrm{kA}, 80 \%$ exceed $20 \mathrm{kA}$, and 5\% exceed $90 \mathrm{kA}$. For the IEEE distribution, the "probability to exceed" values are given by the following equation

$$
P_{I}=\frac{1}{1+(I / 31)^{2.6}}
$$

where $P_{I}$ is in per unit, and $I$ is in $k A$. This equation applies to values of I up to $200 \mathrm{kA}$. Values of $\mathrm{P}_{\mathrm{I}}$ for I varying from 5 to $200 \mathrm{kA}$, computed using equation (1), are given in Table $\mathbf{1}$. The median $(50 \%)$ peak current value is equal to $31 \mathrm{kA}$.

\subsection{Lightning Peak Current - Recent Direct Measure- ments}

More recently direct current measurements on instrumented towers were made in Russia, South Africa, Canada, Germany, Brazil, Japan, and Austria. Important results from the Brazilian, Japanese, and Austrian studies were published during the last decade. Those are reviewed and compared with Berger's data below. Other recent direct current measurements, including those for rocket-triggered lightning, are also considered.

Brazil. Visacro et al. [15] presented a statistical analysis of parameters derived from lightning current measurements on the 60-m Morro do Cachimbo tower near Belo Horizonte, Brazil. A total of 31 negative downward flashes containing 80 strokes were recorded during a period of 13 years. Median peak currents for first and subsequent strokes were found to be 45 and $16 \mathrm{kA}$, respectively, higher than the corresponding values 30 and $12 \mathrm{kA}$, reported for 101 flashes containing 236 strokes by Berger et al. [10]. Possible reasons for the discrepancy include: 1) a relatively small sample size in Brazil; 2) dependence of lightning parameters on geographical location (Brazil versus Switzerland); and 3) different positions of current sensors on the tower at the two locations (bottom of 60-m tower in Brazil versus top of 70-m tower in Switzerland). For typical first strokes (longer rise times), the towers in question are expected to behave as electrically short objects, so that the position of current sensor should not influence measurements. On the other hand, for subsequent strokes (shorter rise times), the towers may exhibit a distributed-circuit behavior, in which case the peak current measured at the bottom of tower is expected to be more strongly influenced by the transient process in the tower compared to the peak current at the top [16-18]. Visacro and Silveira [19], using a hybrid electromagnetic (HEM) model and assuming a 100-m long upward connecting leader, showed that, for typical subsequent-stroke current rise times, peak currents at the top and bottom of the Morro do Cachimbo tower should be essentially the same.

Japan. Takami and Okabe [20] presented lightning return-stroke currents directly measured on 60 transmissionline towers (at the top) whose heights ranged from 40 to 140 m. A total of 120 current waveforms for negative first strokes were obtained from 1994 to 2004. This is the largest sample size for negative first strokes as of today. The median peak current was $29 \mathrm{kA}$, which is similar to that reported by Berger et al. [10], although the trigger threshold in Japan (9 $\mathrm{kA}$ ) was higher than in Switzerland. Interestingly, initial data from this Japanese study (for 35 negative first strokes 
Table 1. The IEEE Peak Current Distribution Given by Equation (1) and Corresponding Values of $D_{\text {soil }}$ Given by Equation (5).

\begin{tabular}{|c|c|c|c|c|c|c|c|c|}
\hline Peak current, I, kA & 5 & 10 & 20 & 40 & 60 & 80 & 100 & 200 \\
\hline$D_{\text {soil }}, m\left(Z=25 \Omega, E_{b}=300 \mathrm{kV} / \mathrm{m}\right)$ & 0.42 & 0.83 & 1.7 & 3.3 & 5.0 & 6.7 & 8.3 & 17 \\
\hline
\end{tabular}

recorded in 1994-1997) yielded the median peak current of $39 \mathrm{kA}[21]$.

Austria. Diendorfer et al. [22] analyzed parameters of 457 upward negative flashes initiated from the $100-\mathrm{m}$ Gaisberg tower in 2000-2007. Upward flashes contain only strokes that are similar to subsequent strokes in downward flashes, i.e., they do not contain first strokes initiated by downward stepped leaders. Many upward flashes contain no strokes at all, only the so-called initial-stage current. The median return-stroke peak current was $9.2 \mathrm{kA}(\mathrm{n}=615$, the largest sample size as of today). For the 553-m CN Tower, Canada, Hussein et al. [23] reported the median value of the initial peak of current pulses measured in 1992-2001 at the top of the tower to be $5.1 \mathrm{kA}$, which is considerably lower than for the Gaisberg tower return strokes, as well as for subsequent strokes in downward lightning and for strokes in rocket-triggered lightning [16]. The discrepancy may be due to inclusion in the Canadian sample of events with current peaks smaller than $1 \mathrm{kA}$, some of which could be associated with the so-called initial-stage pulses, not with return strokes.

Triggered Lightning. Schoene et al. [24] presented a statistical analysis of the salient characteristics of current waveforms for 206 return strokes in 46 rocket-triggered lightning flashes. The flashes were triggered during a variety of experiments related to the interaction of lightning with power lines that were conducted from 1999 through 2004 at Camp Blanding, FL. The return-stroke current was injected into either one of two test power lines or into the earth near a power line via a grounding system of the rocket launcher. The geometric mean return-stroke peak current was found to be $12 \mathrm{kA}$, which is consistent with those reported from other triggered lightning studies (see [25, Table 1]). Further, this parameter was found not to be much influenced by either strike-object geometry or level of man-made grounding, as previously reported by Rakov et al. [26].

\section{ELECTROGEOMETRICAL MODEL (EGM)}

The attachment of the leader to the strike object is often described using the so-called electrogeometrical model (EGM), the core of which is the concept of a "striking distance". This concept obscures some of the significant physics but allows the development of relatively simple and useful techniques for designing lightning protection systems for various structures. The striking distance can be defined as the distance from the tip of the descending leader to the object to be struck at the instant when an upward connecting leader is initiated from this object. It is assumed that at this time the lightning termination point is uniquely determined. For a given striking distance, one can define an imaginary surface above the ground and above objects on the ground (see Fig. 6) such that, when the descending leader passes through that surface at a specific location, the leader is "captured" by a specific point on the ground or on a grounded object. The geometrical construction of this surface can be accomplished simply by rolling an imaginary sphere of radius equal to the assumed striking distance across the ground and across objects on the ground, the socalled rolling sphere method (RSM) (e.g., Lee, 1978 [27]; NFPA 780 [3]). The locus of all points traversed by the center of the rolling sphere forms the imaginary capture surface referred to above. Those points that the rolling sphere touches can be struck, according to this approach; and points where the sphere does not touch cannot. Fig. (7) illustrates the rolling sphere method. The shaded area in Fig. (7) is that area into which, it is postulated, lightning cannot enter.

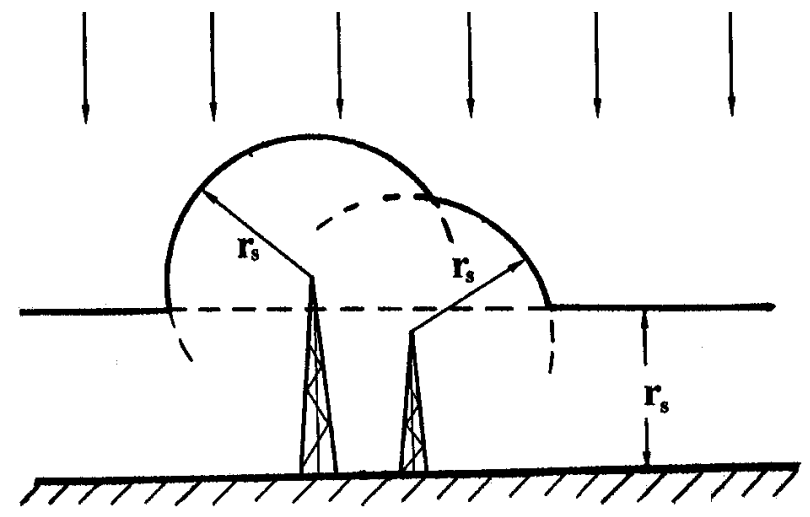

Fig. (6). Illustration of capture surfaces of two towers and earth's surface in the electrogeometrical model. $r_{s}$ is the striking distance. Vertical arrows represent descending leaders, assumed to be uniformly distributed above the capture surfaces. Adapted from Bazelyan and Raizer (2000) [28].

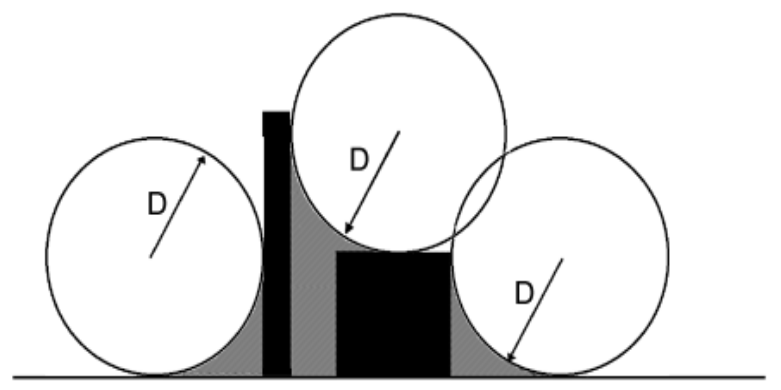

Fig. (7). Illustration of the rolling sphere method for two objects shown in black. $D$ is the striking distance (same as $r_{s}$ in Fig. 6). Shaded area is that area into which, it is postulated, lightning cannot enter. Adapted from Szczerbinski (2000) [29].

In the rolling sphere method, the striking distance is assumed to be the same for any object projecting above the earth's surface and for the earth itself. There are variations of the EGM in which the assumption of different striking distances for objects of different geometry is used (e.g., Eriksson 1987 [30]). The main application of the rolling sphere method is positioning air terminals on an ordinary 
structure, so that one of the terminals, rather than a roof edge or other part of the structure, initiates the upward leader that intercepts the descending leader and, hence, becomes the lightning attachment point.

The striking distance is usually expressed as a function of prospective return-stroke peak current. The procedure to obtain such an expression typically involves assumptions of leader geometry, total leader charge, distribution of charge along the leader channel, and critical average electric field between the leader tip and the strike object at the time of the initiation of upward connecting leader from this object. This critical electric field is assumed to be equal to the average breakdown field from long laboratory spark experiments with rod-rod and rod-plane gaps, which varies with waveshape of applied voltage as well as with other factors such as the high-voltage generator circuitry. The typical assumed values range from 200 to $600 \mathrm{kV} / \mathrm{m}$. As a result, one can obtain an expression relating the striking distance to the total leader charge. In the next step, the observed correlation (see Fig. 8) between the charge and resultant return-stroke peak current (Berger 1972 [9]) is used to express the striking distance, $r_{s}$, in terms of the peak current, I. The most popular striking-distance expression, included in many lightning protection standards, is

$r_{S}=10 \cdot I^{0.65}$

where $\mathrm{I}$ is in $\mathrm{kA}$ and $\mathrm{r}_{\mathrm{s}}$ is in meters. This and other expressions for the striking distance found in the literature are illustrated in Fig. (9). Given all the assumptions involved and large scatter in the experimental charge-current relation (see Fig. 8), each of these relationships is necessarily crude, and the range of variation among the individual expressions (see Fig. 9) is up to a factor of 3 or more. Therefore, there are considerable uncertainties in estimating the striking distance. On the other hand, there is satisfactory long-term (the RSM has been in the Hungarian Standard on Lightning Protection since 1962; Horvath, 2000 [31]) experience with the RSM as applied to placement of lightning rods on ordinary structures and with the EGM in general as applied to power lines. This experience is the primary justification for the continuing use of this method in lightning protection studies.

The EGM can be used for estimating lightning incidence to different elements (usually to the protected object) of a structure as follows. One needs to (1) assume the spatial distribution of descending lightning leaders above all the capture surfaces (see Fig. 6) and specify the ground flash density, $\mathrm{N}_{\mathrm{g}}$ (typically $\mathrm{N}_{\mathrm{g}}=$ const), (2) find the striking distance, $r_{s}(I)$, and then the projection, $S(I)$, of the resultant capture surface of the element in question onto the ground surface, (3) specify the statistical distribution (the probability density function, to be exact) of lightning peak currents, $\mathrm{f}(\mathrm{I})$, and (4) integrate the product $\mathrm{N}_{\mathrm{g}} \times \mathrm{S}(\mathrm{I}) \times \mathrm{f}(\mathrm{I}) \times \mathrm{dI}$ from 0 to $I_{\max }$, to obtain the lightning incidence (number of strikes per year). Alternatively, one can eliminate finding $\mathrm{S}(\mathrm{I})$ in item (2) and entire item (4) from the outlined procedure using the Monte Carlo technique.

\section{BONDING VS ISOLATING APPROACHES IN LIGHTNING PROTECTION PRACTICE}

The twofold objective of structural lightning protection is (1) to force the current flow where one wants it to go and (2) not to allow the development of hazardous potential differences. A difference of potential of $2 \mathrm{MV}$ is sufficient for a sideflash of over $1.8 \mathrm{~m}$ in air (NFPA 780 [3]) or arcing through the soil over $5.4 \mathrm{~m}$ or so. Once arcing takes place, an unplanned and uncontrolled current path is created. The arc is likely to turn moisture in the soil or structural material to steam with potentially damaging hydrodynamic effects. Destructive arcing between exposed or buried elements of

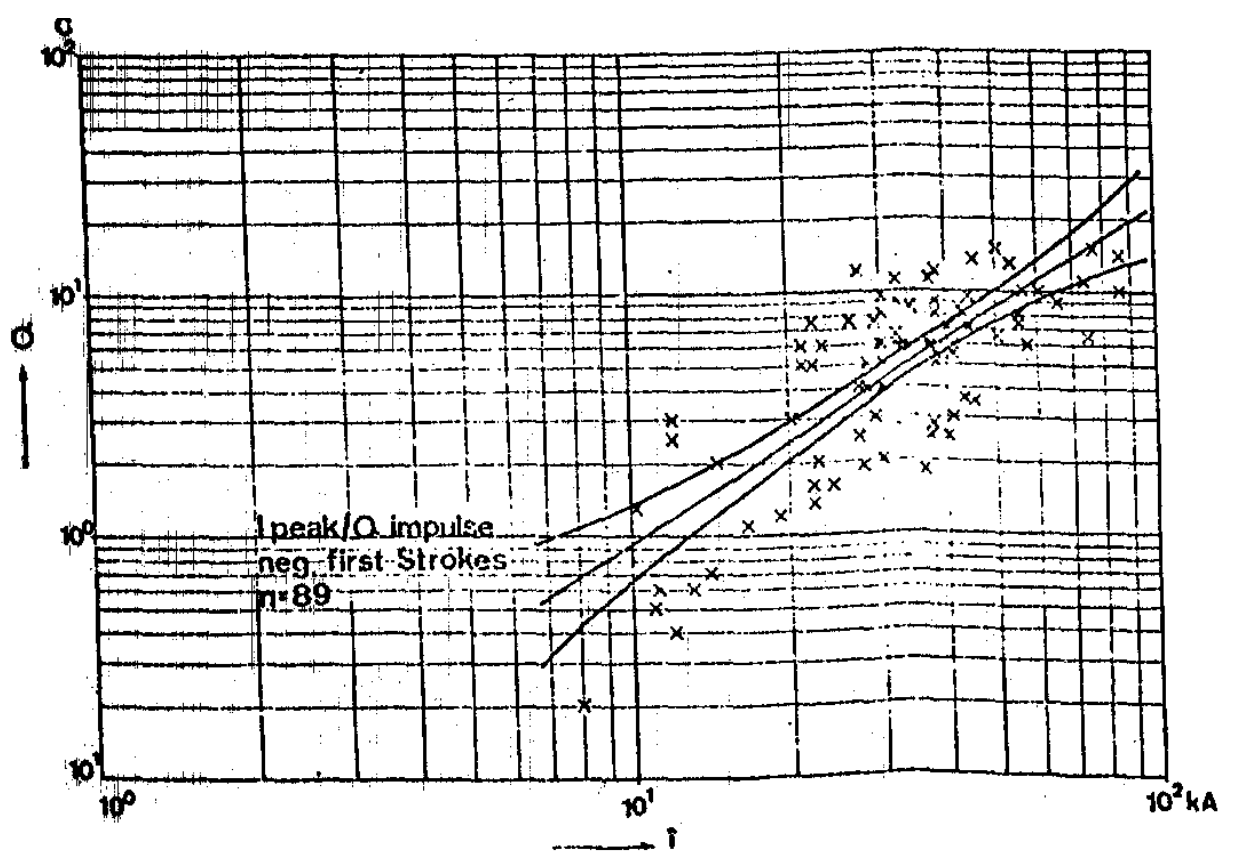

Fig. (8). Scatter plot of impulse charge, Q, versus return-stroke peak current, I, for first strokes in 89 negative flashes in Switzerland. Note that both vertical and horizontal scales are logarithmic. The best fit to data, $\mathrm{I}=10.6 \mathrm{Q}^{0.7}$, where $\mathrm{Q}$ is in coulombs and $\mathrm{I}$ is in kiloamperes, was used in deriving Eq. 2. Adapted from Berger (1972) [9]. 
the lightning protective system (LPS) and nearby metallic objects can be prevented by either (1) equipotential bonding or (2) adequate electrical isolation. If direct bonding is not acceptable, it should be done via a surge protective device (SPD) with suitable characteristics.

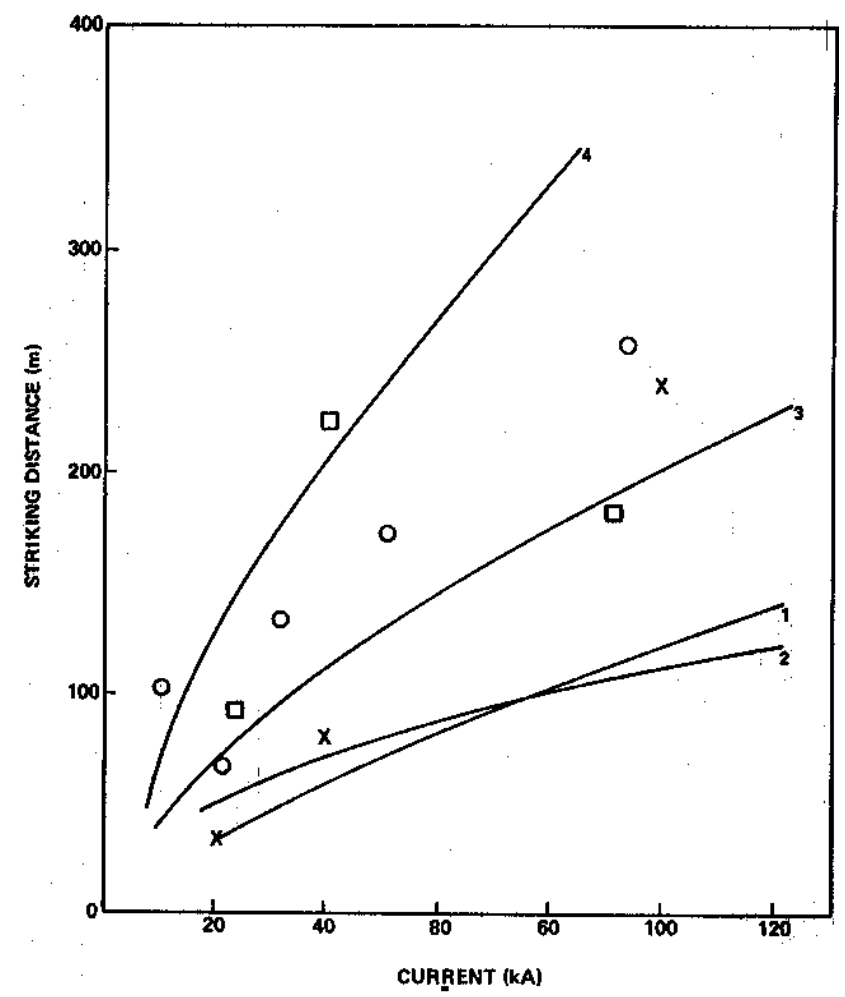

Fig. (9). Striking distance versus return-stroke peak current [curve 1, Golde (1945) [32]; curve 2, Wagner (1963) [33]; curve 3, Love (1973) [34]; curve 4, Ruhling (1972) [35]; x, theory of Davis (1962) [36]; o, estimates from two-dimensional photographs by Eriksson (1978) [37]; $\square$, estimates from three-dimensional photography by Eriksson (1978) [37]. Adapted from Golde (1977) [38] and Eriksson (1978) [37].

Ideally, when lightning current causes a properly protected system's potential to rise momentarily to as much as some megavolts, all points of bonded conductors "rise" together (neglecting traveling-wave effects that occur on electrically long conductors), and no hazardous potential differences are created. This scenario is somewhat similar to that of a bird sitting on a high-voltage wire unaware that it is at a time-varying potential whose amplitude exceeds $1 \mathrm{kV}$.

The choice between the bonding and the isolating approaches usually depends on whether it is possible or not to separate LPS conductors from other conductors of the system by distances that are larger than the so-called safety distance. This safety distance depends on the breakdown electric field (which is different in air and in the soil), the magnitude of the lightning current (also the current rate-ofrise when the inductance of down-conductors is involved), and the impedance "seen" by the lightning at its attachment point (which depends on the soil resistivity, the geometry of the grounding electrode, and, in the case of sideflash in air, on the inductance between the point of interest and the grounding system).
According to Kuzhekin et al. (2003) [39], the distance between an LPS down-conductor and the protected object in air should be greater than $D_{\text {air }}$ (see Fig. 10) given in meters by

$$
D_{\text {air }}=0.12 \cdot Z+0.1 \cdot l . \quad(\mathrm{m})
$$

where $\mathrm{Z}$ is the impedance of LPS grounding system under direct lightning strike conditions (transient impedance, which can be either smaller or larger than the dc grounding resistance, $R$ ) and $\ell$ is the distance between the point of interest and the LPS grounding system. For a point in the immediate vicinity of ground surface, $\ell \approx 0$ and equation (3) reduces to

$$
\begin{aligned}
& D_{\text {air }}=0.12 \cdot Z \quad \text { (m) } \\
& \quad \text { If } Z=25 \Omega, D_{\text {air }}=0.12 \times 25=3 \mathrm{~m} .
\end{aligned}
$$

The distance between the LPS grounding system and buried metallic services should be greater than $D_{\text {soil }}$ given by

$$
D_{\text {soil }}=I \cdot Z / E_{b} \quad(\mathrm{~m})
$$

where $I$ is the lightning peak current, and $E_{b}$ is the breakdown electric field in the soil. Kuzhekin et al. (2003) [39] assumed I $=60 \mathrm{kA}$ (approximately $10 \%$ value, which is recommended for lightning protection studies in Russia) and $\mathrm{E}_{\mathrm{b}}=300 \mathrm{kV} / \mathrm{m}$, so that

$$
D_{\text {soil }}=0.2 \cdot Z \quad(\mathrm{~m})
$$

If $Z=25 \Omega, D_{\text {soil }}=0.2 \times 25=5 \mathrm{~m}$. Whatever the value of Z, Kuzhekin et al. (2003) [39] recommend that $\mathrm{D}_{\text {air }} \geq 5 \mathrm{~m}$ and $D_{\text {soil }} \geq 3 \mathrm{~m}\left(\mathrm{D}_{\text {air }}>\mathrm{D}_{\text {soil }}\right.$ due to the inductance of down conductors). It follows that buried electrical cables within 3 $\mathrm{m}$ of an LPS grounding system must be bonded to that system. An insulated single-wire cable can be bonded either via SPD or via an enclosing metallic pipe. Kuzhekin et al. (2003) [39] state that the capacitance between the cable and pipe is sufficiently large, so that the capacitive impedance between them under direct lightning strike conditions is very small. As a result, the wire and pipe become effectively bonded (at the high frequencies characteristic of lightning current), this effect saving cable's insulation from electrical breakdown.

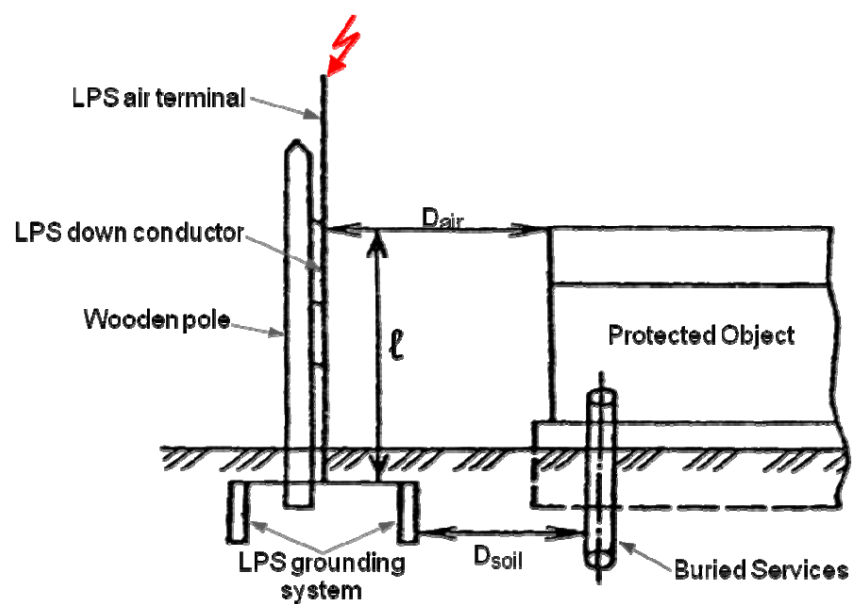

Fig. (10). Illustration of safety distances in air $\left(D_{\text {air }}\right)$ and in the soil $\left(D_{\text {soil }}\right)$. Taken from Kuzhekin et al. (2003) [39]. 
It follows from equation (5) that the lightning safety distance in the soil depends on (1) the magnitude of the lightning peak current, (2) the breakdown electric field in the soil, and (3) the impedance "seen" by the lightning at its attachment point.

We now consider the magnitude of the lightning peak current. Clearly $\mathrm{D}_{\text {soil }}$ increases with increasing I. Lightning peak currents for first strokes vary by a factor of 50 or more, from about $5 \mathrm{kA}$ to $250 \mathrm{kA}$ (e.g., Rakov and Uman, 2003 [5]). The probability of occurrence of a given value of peak current rapidly increases with increasing I, up to $25 \mathrm{kA}$ or so, and then slowly decreases. In designing lightning protective schemes, it is customary to consider, as the "worst case", moderately severe strokes that still have an appreciable probability of occurrence, so that the object is protected against the overwhelming majority of strokes (up to the "worst case"). It seems to be reasonable to consider lightning strokes with peak currents up to $60 \mathrm{kA}$, which constitute about $85 \%$ of the population. In this case, $D_{\text {soil }}=5.0 \mathrm{~m}$. If one would like to assure protection against strokes up to 80 or $100 \mathrm{kA}$, which constitute about 92.2 or $95.5 \%$ of the population, respectively, the corresponding values of $\mathrm{D}_{\text {soil }}$ will be 6.7 or $8.3 \mathrm{~m}$.

Table 1 gives values of $D_{\text {soil }}$ computed using equation (5) for different values of $\mathrm{I}$ (corresponding values of $\mathrm{P}_{\mathrm{I}}$, computed using equation (1), are indicated), assuming that $\mathrm{Z}$ $=25 \Omega$ and $\mathrm{E}_{\mathrm{b}}=300 \mathrm{kV} / \mathrm{m}$. As stated above, a reasonable value of $\mathrm{I}$ in equation (5) is $60 \mathrm{kA}$, and the corresponding value of $D_{\text {soil }}=5 \mathrm{~m}$.

\section{SUMMARY}

Traditional lightning parameters needed in engineering applications include lightning peak current, maximum current derivative (di/dt), average current rate of rise, current risetime, current duration, charge transfer, and action integral (specific energy), all derivable from direct current measurements. Distributions of these parameters presently adopted by most lightning protection standards are largely based on measurements by Berger and coworkers in Switzerland. More recently, direct current measurements on instrumented towers were made in other countries. Important results from the Brazilian, Japanese, and Austrian studies were published during the last decade. Triggered-lightning experiments have provided considerable insight into natural lightning processes.

The lightning protection technique introduced by Benjamin Franklin has proven its effectiveness as evidenced by the comparative statistics of lightning damage to protected and unprotected structures. The rolling sphere method commonly used in the design of such systems is relatively crude, in part, because of our insufficient understanding of the lightning attachment process, but it does represent a useful engineering tool for determining the number and positions of air terminals. Topological shielding with surge protection provides the optimal approach to both structural and surge protection, but it is often costly.

The choice between the bonding and the isolating approaches usually depends on whether it is possible or not to separate LPS conductors and other conductors of the system by distances that are larger than the so-called safety distance. This safety distance depends on the breakdown electric field (which is different in air and in the soil), the magnitude of the lightning current (also the current rate-ofrise when the inductance of down-conductors is involved), and the impedance "seen" by the lightning at its attachment point (which depends on the soil resistivity, the geometry of the grounding electrode, and, in the case of sideflash in air, on the inductance between the point of interest and the grounding system).

\section{ACKNOWLEDGEMENT}

This work was supported in part by NSF grant ATM0852869 .

\section{CONFLICT OF INTEREST}

Declared none.

\section{REFERENCES}

[1] Wiesinger J, Zischank W. Lightning Protection, in Handbook of Atmospheric Electrodynamics. In: Volland H, Ed. Boca Raton: CRC Press 1995; vol. II: pp. 33-64.

[2] UL 96A. Standard for Installation Requirements for Lightning Protection Systems. Underwriters Laboratories 1998.

[3] NFPA 780 (National Fire Protection Association). Standard for the installation of lightning protection systems, Available from NFPA, 1 Batterymarch Park, PO Box 9101, Quincy, Massachusetts 022699101, 2008.

[4] Vance EF. Electromagnetic interference control. IEEE Trans Electromagn Compat 1980; 22: 54-62.

[5] Rakov VA, Uman MA. Lightning: Physics and Effects. UK: Cambridge University Press 2003; p. 687.

[6] IEEE Std 1410-1997 (IEEE Power Engineering Society). IEEE guide for improving the lightning performance of electric power overhead distribution lines. Available from the Institute of Electrical and Electronics Engineers, Inc., 345 East 47th Street, New York, NY 10017, USA.

[7] IEEE Std 1243-1997 (IEEE Power Engineering Society). IEEE guide for improving the lightning performance of transmission lines. Available from the Institute of Electrical and Electronics Engineers, Inc., 345 East 47th Street, New York, NY 10017, USA.

[8] IEC 62305-1 (International Electrotechnical Commission). Protection against lightning, Part 1: General Principles 2006.

[9] Berger K. Mesungen und Resultate der Blitzforschung auf dem Monte San Salvatore bei Lugano. der Jahre 1963-1971. Bull SEV 1972; 63: 1403-22.

[10] Berger K, Anderson RB, Kroninger H. Parameters of lightning flashes. Electra 1975; 41: 23-37.

[11] Bazelyan EM, Gorin BN, Levitov VI. Physical and engineering foundations of lightning protection. Leningrad: Gidrometeoizdat 1978; p. 223.

[12] Anderson JG. Lightning performance of transmission lines in transmission line reference book. $345 \mathrm{kV}$ and Above, Electric Power Research Institute (EPRI), Palo Alto, CA 1982.

[13] Anderson RB, Eriksson AJ. Lightning parameters for engineering application. Electra 1980; 69: 65-102.

[14] CIGRE Document 63. Guide to Procedures for Estimating the Lightning Performance of Transmission Lines, October 1991.

[15] Visacro S, Soares JA, Schroeder LC, Cherchiglia L, de Sousa VJ. Statistical analysis of lightning current parameters: Measurements at Morro do Cachimbo Station. J Geophys Res 2004; 109: 1105-11.

[16] Rakov VA. Transient response of a tall object to lightning. IEEE Trans Electromagn Compat 2001; 43(4): 654-61.

[17] Rakov VA. A review of the interaction of lightning with tall objects. Recent Res Develop Geophys 2003; 5: 57-71.

[18] Baba Y, Rakov VA. Influences of the presence of a tall grounded strike object and an upward connecting leader on lightning currents and electromagnetic fields. IEEE Trans Electromagn Compat 2007; 49(4): 886-92.

[19] Visacro S, Silveira FH. Lightning current waves measured at short instrumented towers: The influence of sensor position. Geophys Res Lett 2005; 32:18804-5.

[20] Takami J, Okabe S. Observational results of lightning current on transmission towers. IEEE Trans Power Deliv 2007; 22(1): 547-56. 
[21] Narita T, Yamada T, Mochizuki A, et al. Observation of current waveshapes of lightning strokes on transmission towers. IEEE Trans Power Deliv 2000; 15(1): 429-35.

[22] Diendorfer G, Pichler H, Mair M. Some parameters of negative upward-initiated lightning to the Gaisberg tower (2000-2007). IEEE Trans Electromagn Compat 2009; 51(3): 443-52.

[23] Hussein A, Janischewskyj W, Milewski M, et al. Current waveform parameters of CN Tower. J Electrostat 2004; 60:149-62.

[24] Schoene J, Uman MA, Rakov VA, et al. Characterization of return stroke currents in rocket-triggered lightning. J Geophys Res 2009; 114: 3106 .

[25] Schoene J, Uman MA, Rakov VA, et al. Statistical characteristics of the electric and magnetic fields and their time derivatives $15 \mathrm{~m}$ and $30 \mathrm{~m}$ from triggered lightning. J Geophys Res 2003; 108(6): 4192.

[26] Rakov VA, Uman MA, Rambo KJ, et al. New insights into lightning processes gained from triggered-lightning experiments in Florida and Alabama. J Geophys Res 1998; 103: 14117-30.

[27] Lee RH. Protection zone for buildings against lightning strokes using transmission line protection practice. IEEE Trans Ind Appl 1978; 14: 465-70.

[28] Bazelyan EM, Raizer YP. Lightning physics and lightning protection. Institute of Physics Publication: Bristol 2000; 325.
[29] Szczerbinski M. A discussion of 'Faraday cage' lightning protection and application to real building structures. J Electrostat 2000; 48: 145-54.

[30] Eriksson AJ. The incidence of lightning strikes to power lines. IEEE Trans 1987: 859-70.

[31] Horvath T. Rolling Sphere - Theory and Application, in Proc. 25th Int. Conf. on Lightning Protection, Rhodes, Grece 2000; pp. 301-5.

[32] Golde RH. On the frequency of occurrence and the distribution of lightning flashes to transmission lines. AIEE Trans 1945; 64(3): 902-10.

[33] Wagner CF. Relation between stroke current and velocity of the return stroke. AIEE Trans Pow Appar Syst 1963; 82: 609-17.

[34] Love ER. Improvements on lightning stroke modelling and applications to the design of EHV and UHV transmission lines. M.Sc. Thesis, University of Colorado 1973.

[35] Rühling F. Modelluntersuchungen über den Schutzraum und ihre Redeutung für Gebäudeblitzableiter. Bull. Schweiz. Elektrotech. 1972; Ver. 63: 522-8,

[37] Eriksson AJ. Lightning and tall structures. Trans S Afr Inst Electr Eng 1978; 69(8): 238-52.

[38] Golde RH. The Lightning Conductor. Lightning. In: Golde RH, Ed. Lightning Protection. New York: Academic Press 1977; vol. 2: pp. 545-76.

[39] Kuzhekin IP, Larionov VP, Prokhorov EN. Lightning and Lightning Protection. Moscow: Znak 2003; p. 300.

(C) Vladimir A. Rakov; Licensee Bentham Open.

This is an open access article licensed under the terms of the Creative Commons Attribution Non-Commercial License (http://creativecommons.org/licenses/by-nc/3.0/) which permits unrestricted, non-commercial use, distribution and reproduction in any medium, provided the work is properly cited. 